\title{
FAIR TRADE FOR ALL: HOW TRADE CAN PROMOTE DEVELOPMENT
}

\section{STIGLITZ, Joseph; CHARLTON, Andrew}

New York: Oxford University Press, 2005.

Alexandre de Freitas Barbosa*

Professor de Economia do Centro de Ciências Sociais Aplicadas da Universidade Presbiteriana Mackenzie, Doutor em Economia Aplicada pelo Instituto de Economia da Unicamp.

E-mail: alexandre@os.org.br

* Agradecemos as sugestões e os comentários do professor Ricardo Amorim. 
[...] No one, not even the representatives of the United States, challenged the charges that we made against the gross inequities of the previous rounds, or even the inequities of some of the proposals then under discussion. But the trade ministers say in private, "What are we to do? Our congresses and parliaments have tied our hands. We live in democracies, and that is part of the price one has to pay for democracy" (STIGLITZ; CHARLTON, p. vi, 2005).

Joseph Stiglitz faz parte de uma espécie estranha e rara de economistas. Depois de ganhar o prêmio Nobel, em 2001, ele não se contentou com a fama eterna e assumiu uma posição cada vez mais iconoclasta com relação aos princípios da economia convencional. Alguns diriam que esta seria tão-somente uma estratégia de marketing, destinada a atrair um segmento ainda mais amplo: os não-economistas ou os inconformados com o imperialismo da ciência econômica.

Independentemente de qual seja a avaliação de seu leitor, não se pode negar que a opção do principal economista em atividade no atual mundo globalizado - pelas qualidades analíticas e também pela abordagem crítica e original acerca dos principais temas do mundo contemporâneo - rende frutos alvissareiros. Depois de chegar ao ápice das honras aristocráticas e dos modelos rebuscados, é como se decidisse retornar ao mundo dos plebeus e da realidade empírica. Vejamos algumas de suas publicações no Brasil após o ingresso no mundo dos sábios.

Stiglitz ficou mais conhecido do grande público brasileiro ao lançar em português o livro Globalization and its discontents (2002) - o título é uma paródia ao famoso livro de Sigmund Freud, que foi rotundamente desprezado pela edição brasileira. Esse livro foi intitulado como A globalização e seus maleficios, mas a tradução correta seria "O mal-estar da globalização". O autor apresenta os limites e as debilidades do processo de globalização, mostrando que esta não é acompanhada de uma nova institucionalidade internacional adequada ao novo momento do capitalismo, terminando assim por ampliar as desigualdades Norte/Sul.

Em 2003, nosso autor voltaria às livrarias brasileiras com outro livro, focando a realidade norte-americana (STIGLITZ, 2003). Tendo sido membro e presidente do Conselho de Consultores Econômicos, durante o primeiro governo Clinton, Stiglitz não poupa o presidente do partido democrata por suas escolhas econômicas que o fizeram curvar-se a um forte ajuste fiscal e ao atendimento dos interesses do capital financeiro. 
Recentemente, Stiglitz publicou Fair trade for all: how trade can promote development (2005), escrito com o economista Andrew Charlton, da London School of Economics. Mais uma vez, o próprio título da obra seria canibalizado. A edição brasileira, talvez por cacoete ideológico, inverteu os termos da equação e substituiu "Comércio justo para todos" por "Livre mercado para todos", fazendo contradizer o conteúdo da obra com o título ostentado na capa.

Nessa obra, Stiglitz e seu co-autor desmistificam o significado supostamente "desenvolvimentista" da atual Rodada Doha. O mais interessante é que o prognóstico pessimista sobre o avanço das negociações na OMC foi proferido ao final de 2005, antes da reunião ministerial de Hong Kong, quando ainda não se avizinhava a possibilidade de suspensão das negociações - fato ocorrido no final de junho de 2006. Lembremo-nos ainda que Stiglitz ocupou o cargo de economista-chefe do Banco Mundial, quando então se opôs ao antídoto recomendado pelo FMI na seqüência da crise asiática.

O livro está estruturado da seguinte maneira. Em primeiro lugar, são discutidas as relações entre comércio e crescimento, do ponto de vista teórico, mas partindo de experiências históricas concretas. Em segundo lugar, resgata-se a história do sistema multilateral de comércio, desde a Rodada Uruguai até a Rodada Doha - que não atende, no entender dos autores, as necessidades de uma economia crescentemente integrada e onde as desigualdades Norte/Sul se ampliam de forma categórica. Em terceiro lugar, são apontadas algumas das precondições para que tenha lugar uma rodada vantajosa para os países pobres; o que, para os autores, não significa que esta deva ser prejudicial aos países ricos, antes pelo contrário. Finalmente, nas conclusões é apontado o que deveria ser negociado e o que não poderia estar na agenda, caso o sistema multilateral de comércio passe a ser encarado como uma das engrenagens capazes de efetivamente enfrentar as questões da pobreza e da desigualdade.

Quanto à discussão teórica inicial, Stiglitz e Charlton (2005) preferem se afastar dos cenários hipotéticos e irreais da teoria econômica convencional, que supõe uma escolha binária entre liberdade de comércio e autarquia. $\mathrm{Na}$ prática, existe um grande espectro de possibilidades concretas, as quais definem os vários regimes de comércio. Os benefícios da liberalização não são negados, mas vistos como dependentes das várias circunstâncias nacionais e da capacidade de seqüenciamento e gradualismo das políticas.

Merecem relevo as experiências do Sudeste Asiático e da América Latina no pós-Segunda Guerra Mundial. No primeiro caso, ressaltam-se o papel ativo do Estado, a política comercial em dois trilhos (exportadora dos produtos mais competitivos e protecionista nas indústrias nascentes) e a estrita 
regulação à entrada de empresas multinacionais. Na experiência latino-americana, os autores isentam as políticas de substituição de importações de boa parte das críticas recebidas pelo mantra neoliberal. Sua principal debilidade estaria na abertura irrestrita aos fluxos de capital privado internacionais (tanto das multinacionais quanto por via de empréstimos bancários). A virada da conjuntura mundial transformaria essas fraquezas num colapso chamado "crise da dívida externa". Isso parece até discurso de economista heterodoxo brasileiro, mas escrito por um prêmio Nobel na língua do capitalismo globalizado.

Obviamente, não se trata de fazer uma defesa irrestrita do modelo de industrialização latino-americano, mas de aceitar que a expansão do mercado interno, juntamente com as políticas de comércio exterior e industriais implantadas, foram, em grande medida, responsáveis pela diversificação da pauta de exportações desses países - como atesta outro grande economista gringo, Dani Rodrik (2004). Isso não quer dizer que os resultados potenciais dessas políticas tenham sido plenamente aproveitados.

Vale lembrarmos que, nessa discussão, Stiglitz herda vários cacoetes de seu passado de economista do mainstream, especialmente quando busca um equilíbrio correto entre Estado e mercado, tentando impedir que as falhas de um não levem à emergência das falhas de outro. Talvez fosse o caso de aprender com Peter Evans (2004), quando este insiste que existem diferentes estruturas de Estado e de relações Estado-sociedade, as quais se combinam de acordo com realidades históricas específicas.

Mas voltemos ao Stiglitz rebelde. Quais são os problemas com a teoria convencional? Em nenhum momento, ele e seu co-autor questionam que o aumento do comércio possa trazer maior eficiência e promover o crescimento econômico. O problema está no fato de que as premissas por trás do modelo são assaz restritivas. Senão vejamos.

Assume-se plena utilização dos fatores produtivos, descarta-se a vulnerabilidade dos mercados externos, não se cogita que os mecanismos de preços não funcionam plenamente quando vários setores econômicos ainda não foram internalizados, e sequer se discute sobre os vencedores e perdedores do processo de abertura, partindo-se da visão singela de que uns mais do que compensam os outros.

Provavelmente, Stiglitz não leu Prebisch e Furtado, porque, quando estava estudando economia, esses autores eram vistos como lunáticos latino-americanos que pensavam estar fazendo ciência, mas deixavam de lado algumas das premissas do pensamento hegemônico ocidental. O que Stiglitz e Charlton (2005) escrevem na introdução teórica de seu livro, além de ser pouco original, e defasado em cerca de 40 anos, merece respeito pela credibilidade de 
quem assume - provavelmente sem conhecer - influências teóricas de outros. É verdade, porém, que ele desenvolve argumentos não plenamente desenvolvidos nos tempos da Cepal, como a importância das externalidades de informação e da imperfeição dos mercados de capitais, que inviabilizariam a equação abertura = eficiência $=$ menor desigualdade.

Assim, tem-se a defesa da adoção de políticas de liberalização desde que tecidas de acordo com cada realidade nacional, não havendo um único modelo a ser usado por todos os países. Sobre o FMI, os autores afirmam que essa instituição daria uma melhor contribuição se assegurasse a estabilidade do sistema financeiro global, no lugar de pregar acriticamente em favor do livre comércio.

Num segundo momento, Stiglitz e Charlton (2005) recuperam a história do sistema multilateral de comércio, situando o foco da análise nas negociações intrincadas e desbalanceadas da Rodada Doha. Os autores apontam como, até a Rodada Uruguai, as negociações no âmbito do GATT se circunscreviam aos produtos industriais, especialmente aqueles de interesse dos países desenvolvidos. Não havia pressão por liberalização sobre os países em desenvolvimento. No entanto, a consolidação da Comunidade Européia serviria paradoxalmente como estímulo ao multilateralismo. Tanto a Rodada Kennedy (do início da década de 1970) como a Rodada Uruguai (de meados dos anos 1980) contariam com apoio entusiástico dos Estados Unidos.

A Rodada Uruguai foi vista como uma ruptura na trajetória do sistema multilateral de comércio. Os países em desenvolvimento, então, passaram a se ver na mesa de negociação - seus mercados passam a ser cobiçados! - e alguns temas surgiram repentinamente na agenda (serviços, investimentos e propriedade intelectual). O tema agricultura foi incluído - hoje se sabe - apenas na retórica, enquanto no setor têxtil e vestuário a liberalização se prorrogaria por dez anos depois da criação da OMC no ano de 1995.

Não é à toa que os supostos resultados positivos prognosticados para os países em desenvolvimento não se cumpriram. Segundo Stiglitz e Charlton (2005), foi porque os modelos utilizados partiam de hipóteses irrealistas ou ainda porque o acertado não foi entregue. De fato, segundo estimativas do Pnud citadas pelos autores, os 48 países de menor desenvolvimento relativo sofreram perdas líquidas de US\$ 600 milhões.

Além dos problemas relacionados à manutenção dos subsídios agrícolas pelas grandes potências - acarretando uma pressão baixista sobre os preços destas commodities -, o TRIPS (acordo de propriedade intelectual) cumpriria um papel extremamente perverso ao criar monopólios temporários para empresas dos países desenvolvidos, comprometendo a saúde pública dos mais pobres. 
Quanto à Rodada Doha, houve seu bombástico lançamento no ano de 2001 (alguns meses depois do ataque às torres gêmeas), e seu foco "desenvolvimentista", voltado para a agenda dos países mais pobres, e especialmente para o tema agricultura, teve como promessa nada menos que a redução da pobreza. Apesar disso, nossos autores mostram como, aos poucos, ela foi se desviando de seu eixo inicial.

Em 2002, os Estados Unidos aprovariam a nova Farm Bill, aumentando o montante de subsídios, ao passo que a revisão da Política Agrícola Comum da União Européia, em 2003, traria resultados pífios. Paralelamente, ambas potências comerciais trataram de pressionar pela continuidade da agenda pósRodada Uruguai, tentando avançar em Doha nos temas de investimentos, compras governamentais, facilitação de comércio e política de concorrência (os chamados "temas de Cingapura"). Trataram, assim, de "chutar a escada" (CHANG, 2004) e impedir um reposicionamento das várias economias em desenvolvimento na divisão internacional do trabalho.

Então, o inesperado se manifestou. Depois de uma década de liberalização e assinatura de acordos com o FMI - que, em parte, explicam por que o PIB per capita da América Latina e da África se expandiu a níveis inferiores ao da média mundial - ouviu-se um rotundo "basta!": 77 países em desenvolvimento se colocaram de forma contrária aos temas de Cingapura. O tema de propriedade intelectual também entrou fortemente na agenda, mas com sinal contrário, forçando os Estados Unidos a alterar a posição de mera defesa dos interesses de suas multinacionais. Na questão do algodão, pequenos países africanos - cujas exportações de algodão representavam $40 \%$ do total de suas vendas externas - "exigiram" dos Estados Unidos o fim dos subsídios.

Essas pressões provenientes de todos os lados foram simplesmente descartadas pelas grandes potências que procuraram, em setembro de 2003, forçar a aprovação de um texto sem o aval dos países em desenvolvimento. Dois anos depois do lançamento da Rodada Doha e dois anos antes da data então prevista para seu término (janeiro de 2005), o que logrou as grandes potências foi incentivar a formação de novas coalizões de poder, tais como G-20, G-33 e G-90, reunindo países em desenvolvimento que batalham por temas específicos.

A história acima relatada - de conhecimento de muitos especialistas, mas que vem agora sob a pena de Stiglitz, além de recheada de testes empíricos e citações requintadas - avançou parcialmente em 2004, quando no âmbito do "pacote de julho", definiu-se uma agenda mais restrita, concentrada especialmente nos temas de acesso a mercado (agricultura e bens industriais, sob a sigla Nama, além de serviços). 
Isso porque o prognóstico continua pouco alentador para uma rodada que se quisera do desenvolvimento. Os desequilíbrios mantiveram-se gritantes nas negociações, enquanto os países desenvolvidos recusaram-se a aceitar a emergência de nova estrutura de poder e de comércio internacional. Vejamos por quê.

De forma sintética, podemos dizer que no tema agrícola - que representa em média 70\% dos empregos nos países em desenvolvimento - não houve qualquer avanço. Segundo outro especialista no tema, Marthin Khor (2006), propõe-se uma redução de tarifas de acordo com diferentes percentuais para as várias bandas. Não existe, portanto, um corte dramático para as maiores tarifas nem um teto tarifário. Aliás, os países desenvolvidos recusam-se a aceitar um teto de 100\%. Além disso, discutem-se flexibilidades de $8 \%$ a $15 \%$ das linhas tarifárias, sem considerar sua participação no valor total das importações. Em outras palavras, produtos estratégicos para esses países podem ficar de fora da agenda negociadora. Quanto aos subsídios domésticos, especialmente os Estados Unidos aceitam (quando muito) reduzir o montante permitido para o que já se pratica, sem impactos em termos de fluxos de comércio.

Dessa forma, bem diferente das negociações de Nama (bens industriais) que afetam mais os países em desenvolvimento, pois possuem tarifas mais elevadas - e onde o corte é não-linear, afetando principalmente as maiores tarifas e impondo um teto tarifário (que é exatamente igual ao valor do coeficiente a ser utilizado na chamada "fórmula suíça", já acordada por pressão dos países ricos). No caso do coeficiente 20 , por exemplo, o teto seria de $20 \%$ para os países em desenvolvimento ${ }^{2}$. Além disso, as flexibilidades - ou seja, linhas tarifárias que podem ficar de fora do corte - não podem superar a casa de 5\%, desde que não afetem mais do que $5 \%$ do valor das importações. Não seria, portanto, um exagero afirmar que a lógica das negociações impõe uma reciprocidade mais que total para os países em desenvolvimento (CHANG, 2005).

Já nas negociações serviços, para Stiglitz e Charlton (2005), tem-se privilegiado a abertura de setores como de telecomunicações e financeiro, sem preocupação com os impactos muitas vezes perversos em termos de redução da concorrência, de elevação de preços e de não-atendimento a setores de baixa renda. Se dependessem dos países desenvolvidos, as negociações atuais do GATS (acordo de serviços) limitariam o espaço para a "regulação doméstica". Adicionalmente, sequer se cogita a possibilidade de abertura, por exemplo, do movimento natural de pessoas (o chamado "modo 4"), especialmente nos segmentos de serviços intensivos em trabalho.

2 Para mais detalhes sobre essas negociações, ver Relatório de Pesquisa do Observatório Social... (2005). 
O assunto é, com certeza, complexo. Os autores têm a preocupação, por exemplo, de apontar que o fim dos subsídios não significaria o nirvana para os países mais pobres. Para alguns países e produtos, a retirada da oferta dos países desenvolvidos levaria a uma elevação dos preços. Haveria, assim, a necessidade de se abrir mais rapidamente os mercados dos bens onde os países em desenvolvimento são exportadores líquidos e não importadores líquidos, além de se fornecer os mecanismos de assistência adequados para os países mais prejudicados, os quais seriam financiados com recursos hoje direcionados para os subsídios domésticos dos países desenvolvidos. Estes deveriam ademais ser forçados a reduzir drasticamente o uso de políticas anti-dumping, direitos compensatórios, salvaguardas e restrições sanitárias, que funcionam como protecionismo disfarçado.

Mas o problema central parece residir nas premissas por trás das negociações comerciais. Segundo os autores, a OMC emerge como uma "instituição mercantilista", na qual a defesa do interesse nacional se mistura a ortodoxias econômicas cuja função é convencer o "inimigo"; ou seja, o problema não é o de obter livre mercado para todos. Ao contrário, faz-se necessário lograr mais mercado e condições de inserção externa para os países mais pobres, que devem poder calibrar suas políticas de abertura de acordo com suas metas e opções de desenvolvimento.

Seria então possível alterar a atual lógica prevalecente nas negociações e incluir o conceito de justiça nas relações internacionais? Se este é o ponto de partida, a agenda deve ser progressiva, trazendo mais benefícios para os países em desenvolvimento. A questão não se refere somente ao conteúdo e ao escopo dos temas cobertos, mas envolve também a forma e a estrutura das negociações.

Estudos de impacto sobre o emprego e as condições sociais devem ser prévios a qualquer rodada. Os custos de ajuste para os mais pobres devem ser mensurados assim como criados mecanismos para sua compensação. A condição inicial de cada país deve ser avaliada, tratando desiguais de forma desigual. Mais que isso, as relações desiguais de poder no âmbito da OMC, agravadas pelas intervenções do FMI, devem ser levadas em consideração.

Ao mesmo tempo, é preciso coibir a invasão do espaço das políticas públicas de desenvolvimento nacional pelas negociações da OMC, devendo-se inclusive voltar atrás nos acordos existentes relativos a investimentos e patentes. Senão como aceitar que meio ambiente e direitos humanos e trabalhistas - por serem trade-related - fiquem de fora da agenda multilateral de comércio?

Se temos em mente que Stiglitz não representa nenhuma ONG ambientalista e tampouco está de braços dados em passeatas com o movimento sindi- 
cal internacional - preferindo os ambientes repletos de laptop, powerpoint e ar-condicionado do poder global -, chegamos à conclusão que o que ele propõe, de fato, é uma restrição da agenda da OMC aos temas estritamente comerciais - com ganhos expressivos para os países em desenvolvimento, e dentre estes os mais pobres. Mais que defender acriticamente a tese da indústria nascente, esse autor quer que as políticas que aflorem desse marco teórico não sejam inviabilizadas enquanto a proteção à indústria adulta prolifera nos países desenvolvidos!

Já que não era nosso intuito discutir a "fórmula" proposta por Stiglitz e Charlton (2005) para a viabilização de uma efetiva liberalização de comércio, pautada pelo princípio do "tratamento especial e diferenciado", cabe dizer que qualquer reformulação efetiva das negociações exige uma reforma institucional da OMC. As reuniões a portas fechadas de um pequeno grupo de países - estilo Green Room meetings - devem ceder espaço a esquemas mais representativos da diversidade encontrada nos cerca de 150 países que compõem a OMC. Paralelamente, os autores sugerem a criação de um novo organismo no seio dessa entidade que possa avaliar os impactos da abertura sobre os países em desenvolvimento.

"Ingênuo", dirão alguns. "Cuspiu no prato que comeu", retrucarão outros. "Tentando salvar o capitalismo de sua crise final", anteciparão outros. Porém, é inegável que do eco alcançado por essa crítica proveniente do establishment acadêmico e econômico - tal como lorde Keynes fizera há 70 anos - depende o futuro do sistema internacional e daquilo que hoje se chama "globalização". Enfim, Stiglitz pôs o dedo na ferida!

\section{Referências}

CHANG, H.-J. Chutando a escada: a estratégia de desenvolvimento em perspectiva histórica. São Paulo: Ed. Unesp, 2004.

Why developing countries need tariffs?: how WTO Nama negotiations could deny developing countries' right to a future. South Centre, Geneve, Nov. 2005.

EVANS, P. Autonomia e parceria: estados e transformação industrial. Rio de Janeiro: Ed. UFRJ, 2004.

KHOR, M. A development assessment of the current WTO negotiations, Third World Network, Sept. 2006. 
Revista de Economia Mackenzie • Volume 4 • n. 4 • 2006 • p. 154-164

RELATÓRIO DE PESQUISA DO OBSERVATÓRIO SOCIAL, OMC. Desigualdades Norte/Sul e a Geopolítica do Desenvolvimento: as negociações do Nama e os impactos sobre a América Latina e o Brasil. São Paulo: IOS, 2005.

RODRIK, D. Industrial policy for the twenty-first century, 2004. Disponível em: <www.ksg.harvard. edu/rodrik>.

STIGLITZ, J. A globalização e seus malefícios. São Paulo: Futura, 2002.

. Globalization and its discontents. London: Penguin Books, 2002.

. Os exuberantes anos 90: uma nova interpretação da década mais próspera da história. São Paulo: Companhia das Letras, 2003.

STIGLITZ, J.; CHARLTON, A. Fair trade for all: how trade can promote development. New York: Oxford University Press, 2005. 
Copyright of Revista de Economia Mackenzie is the property of Universidade Presbiteriana Mackenzie, Revista de Economia Mackenzie and its content may not be copied or emailed to multiple sites or posted to a listserv without the copyright holder's express written permission. However, users may print, download, or email articles for individual use. 